\title{
Optimization of factors affecting Agrobacterium-mediated transformation of Micro-Tom tomatoes
}

\author{
M. Guo, Y.L. Zhang, Z.J. Meng and J. Jiang \\ Key Laboratory of Protected Horticulture Ministry of Education, \\ College of Horticulture, Shenyang Agricultural University, \\ Shenyang, P.R. China \\ Corresponding author: J. Jiang \\ E-mail:jj_syau@hotmail.com
}

Genet. Mol. Res. 11 (1): 661-671 (2012)

Received August 8, 2011

Accepted January 9, 2012

Published March 16, 2012

DOI http://dx.doi.org/10.4238/2012.March.16.4

\begin{abstract}
Micro-Tom is the smallest known variety of tomatoes. An orthogonal experimental design $\mathrm{L}_{16}\left(4^{5}\right)$ was used to optimize Agrobacterium-mediated transformation of cotyledon explants of Lycopersicon esculentum cv. Micro-Tom. Four parameters were investigated to determine their effect on transformation frequency: the concentration of bacterial suspension, time of dip in bacterial suspension, co-cultivation time, and concentration of carbenicillin. We also examined the effect of these parameters on contamination rate, necrosis rate, mortality, cutsurface browning rate, and undamaged explant rate. Both the bacterial and carbenicillin concentrations had a significant influence on the rate of infected explants. The time of co-cultivation also had a significant influence on the transformation parameters. The optimal transformation protocol consisted of an Agrobacterium suspension of $0.5 \times 10^{8}$ cells $/ \mathrm{mL}\left(\mathrm{OD}_{600}=0.5\right)$ and an infection time of $5 \mathrm{~min}$, one day of co-cultivation and $500 \mathrm{mg} / \mathrm{L}$ carbenicillin. Under these conditions, the transformation efficiency of the shoots reached 5.1\%; the mean transfor-
\end{abstract}


mation frequency was $3.9 \%(\mathrm{~N}=838)$.

Key words: Orthogonal design; Micro-Tom; Tissue culture; Hygromycin phosphotransferase gene

\section{INTRODUCTION}

A miniature dwarf tomato (Lycopersicon esculentum), Micro-Tom, is a model cultivar for tomato functional genomics. This cultivar has several unique features, including small size and short life cycle, which allow the mature fruit to be harvested within 70-90 days after sowing. Establishing a high-throughput transformation protocol for Micro-Tom was simple using Agrobacterium (Meissner et al., 1997).

Previous analyses of Agrobacterium-mediated tomato transformation protocol optimization examined only the merits of classical fractional factorial design, such as explants, feeder layers, time of preculture, inoculation with Agrobacterium tumefaciens, co-cultivation, and antibiotic concentration (Xia et al., 2004; Hui et al., 2007; Zen and Cheng, 2008; Ling et al., 2009). This method requires a large number of experiments that can become expensive, however, as mass transfer depends on several variables. In fact, both the main effects of the variables and the interactions among variables should be considered, because these interactions exist in many parametrical problems.

Orthogonal design, the theory and methodology as well as source and characteristics of which have been described elsewhere, is a sophisticated time- and cost-saving testing strategy that draws an orthogonal array to pinpoint areas in which variations may be successfully reduced (Ross, 1988). With probability theory, mathematical statistics, and experience as the basis, the use of a standardized orthogonal table to design experiment, calculate and analyze results, and quickly find an optimal scheme is an efficient treatment of multivariate optimization methods in scientific computing. In addition to keeping the merits of classical fractional factorial design, this strategy takes into account the interactive effects among variables. Optimization of transformation protocols using an orthogonal experimental design reduces the number and cost of experiments (Min, 2009), shortens the protocol selection time, and increases transformation frequencies.

Transformation frequencies were found to be very poor when the hygromycin phosphotransferase gene (HPTII) was used as the selection agent. Etiolation occurred when the regeneration shoots were growing for a time period, and obtaining surviving plants was difficult (Zen and Cheng, 2008). Therefore, the involvement of HPTII in the transformation protocol of Micro-Tom required further optimization. In this study, we established a high-throughput transformation protocol for Micro-Tom through design and analyses resulting from orthogonal design. This protocol could become a powerful tool for functional genomics in tomatoes.

\section{MATERIAL AND METHODS}

\section{Plant materials}

Seeds of L. esculentum Mill. cultivar Micro-Tom was surface sterilized in $70 \%(\mathrm{v} / \mathrm{v})$ ethanol for $30 \mathrm{~s}$ and in $10 \%(\mathrm{v} / \mathrm{v})$ sodium hypochlorite solution with one drop of Tween- 80 for $10 \mathrm{~min}$ and then rinsed three times in sterilized distilled water. The seeds were germinated in 
a conical flask with $40 \mathrm{~mL}$ Murashige and Skoog (MS) medium (Murashige and Skoog, 1962) with $15 \mathrm{~g} / \mathrm{L}$ sucrose and $3 \mathrm{~g} / \mathrm{L}$ plant agar. The $\mathrm{pH}$ was adjusted to 5.8. All cultures were maintained at $25^{\circ} \mathrm{C}$ under a 16 -h light $/ 8$-h dark photoperiod with a light intensity of $60 \mu \mathrm{mol} \cdot \mathrm{m}^{-2} \cdot \mathrm{s}^{-1}$. For the genetic transformation, the seedlings were used when the cotyledons expanded fully and the true leaves were 1 to $2 \mathrm{~mm}$ in length.

\section{Orthogonal design}

An orthogonal experimental design $\mathrm{L}_{16}\left(4^{5}\right)$ (Table 1) was used to evaluate the effects of bacterial suspension concentration, time of dip in bacterial suspension, co-cultivation time, and carbenicillin concentration on transformation frequencies after infection with Agrobacterium. Data analysis was performed with DPS v7.05. Optimal conditions for productivity were determined based on five parameters at four different levels. Every orthogonal combination contained 7-10 explants, and each experiment was repeated twice.

Table 1. Orthogonal design for Agrobacterium-mediated transformation protocol of Micro-Tom $\mathrm{L}_{16}\left(4^{5}\right)$.

\begin{tabular}{lcccc}
\hline Orthogonal combination & $\begin{array}{c}\text { Concentration of bacterial } \\
\text { suspension }\left(\mathrm{OD}_{600}\right)\end{array}$ & $\begin{array}{c}\text { Time of dip in bacterial } \\
\text { suspension (min) }\end{array}$ & $\begin{array}{c}\text { Co-cultivation } \\
\text { time (days) }\end{array}$ & $\begin{array}{c}\text { Concentration of } \\
\text { carbenicillin }(\mathrm{mg} / \mathrm{L})\end{array}$ \\
\hline 1 & 0.2 & 1 & 1 & 2 \\
2 & 0.3 & 5 & 3 & 300 \\
3 & 0.5 & 10 & 4 & 400 \\
4 & 0.7 & 15 & 4 & 500 \\
5 & 0.2 & 5 & 3 & 400 \\
6 & 0.3 & 1 & 2 & 500 \\
7 & 0.5 & 15 & 1 & 200 \\
8 & 0.7 & 10 & 2 & 300 \\
9 & 0.2 & 10 & 4 & 500 \\
10 & 0.3 & 15 & 3 & 400 \\
11 & 0.5 & 1 & 3 & 300 \\
12 & 0.7 & 15 & 4 & 200 \\
14 & 0.2 & 10 & 1 & 300 \\
15 & 0.3 & 5 & 2 & 500 \\
\end{tabular}

\section{Agrobacterium preparation}

Agrobacterium strain EHA105 with appropriate plasmids pCAMBIA1300-2A11-INH (constructed in our laboratory) was used for this study. The chimeric HPTII gene on pCAMBIA1300 conferred to transformed plant cells the capability to grow on medium containing hygromycin. This strain was grown overnight at $28^{\circ} \mathrm{C}$ and $200 \mathrm{rpm}$ in $5 \mathrm{~mL}$ yeast extract beef medium containing 50 $\mathrm{mg} / \mathrm{L}$ kanamycin and $100 \mathrm{mg} /$ Lrifampicin. One milliliter of the bacterial suspension (optical density at $600 \mathrm{~nm}\left[\mathrm{OD}_{600}\right] \approx 1.0$ ) was placed in $50 \mathrm{~mL}$ yeast extract beef medium and centrifuged with various $\mathrm{OD}_{600}$ values $(0.2,0.3,0.5$, and 0.7$)$. The bacteria were resuspended in the same volume of MS medium with $100 \mu \mathrm{M} / \mathrm{L}$ acetosyringone and used for Agrobacterium inoculation.

\section{Transformation method}

Cotyledons were sectioned into two halves across the midvein region. The end of each 
cotyledon was cut to allow it to adsorb the bacterial suspension. The explants were dipped in the bacterial suspension for $1,5,10$, or 15 min and blotted dry on a sterilized paper towel. The explants were placed in co-cultivation medium ( $\mathrm{pH}$ 5.8) containing MS salts, $30 \mathrm{~g} / \mathrm{L}$ sucrose, 3 $\mathrm{g} / \mathrm{L}$ agar, and $1.5 \mathrm{mg} / \mathrm{L}$ zeatin. The plate was incubated in darkness for $1,2,3$, or 4 days at $25^{\circ} \mathrm{C}$. The explants were subcultured into callus induction medium ( $\mathrm{pH}$ 5.8) containing MS salts, 30 $\mathrm{g} / \mathrm{L}$ sucrose, $3 \mathrm{~g} / \mathrm{L}$ agar, $1.5 \mathrm{mg} / \mathrm{L}$ zeatin, $24 \mathrm{mg} / \mathrm{L}$ hygromycin, and 200, 300, 400, or $500 \mathrm{mg} / \mathrm{L}$ carbenicillin sodium. When calli with shoot buds formed from the cotyledon fragment, the zeatin concentration was adjusted to $1 \mathrm{mg} / \mathrm{L}$ (shoot elongation medium). When calli with adventitious buds developed from the explants, the cotyledons were cut off and transferred to a new conical flask containing shoot elongation medium for shoot elongation. When a stem developed in addition to a leaf, the stem was cut off at the maximum possible length and transferred to new shoot elongation medium. When a stem developed in addition to a leaf, they were cut and transferred to rooting medium. The rooting medium ( $\mathrm{pH} 5.8$ ) contained MS medium with $0.05 \mathrm{mg} / \mathrm{L}$ NAA, $15 \mathrm{~g} / \mathrm{L}$ sucrose, $3 \mathrm{~g} / \mathrm{L}$ agar, $17 \mathrm{mg} / \mathrm{L}$ hygromycin, and $500 \mathrm{mg} / \mathrm{L}$ carbenicillin sodium.

\section{Polymerase chain reaction (PCR) analysis}

Genomic DNA was extracted from the in vitro grown leaves of putative transgenic plants using a plant total DNA extract kit (TIANGEN BIOTECH Co., Ltd., Beijing, China) and analyzed using PCR amplification using primers for HPTII (hpt-forward: 5'-TTGGCGACCTCGTATTGGGA-3', hpt-reverse: 5'-CAAGACCTGCCTGAAACCGAA$\left.3^{\prime}\right)$. Plasmid DNA and untransformed plant DNA were used as positive and negative controls, respectively. The amplification conditions consisted of pre-denaturation at $94^{\circ} \mathrm{C}$ for $10 \mathrm{~min}$, denaturation at $94^{\circ} \mathrm{C}$ for $30 \mathrm{~s}$, annealing at $55^{\circ} \mathrm{C}$ for $30 \mathrm{~s}$, and extension at $72^{\circ} \mathrm{C}$ for $45 \mathrm{~s}$ for a total of 30 cycles with a final extension at $72^{\circ} \mathrm{C}$ for $10 \mathrm{~min}$. The reaction products $(392 \mathrm{bp})$ were separated on $1.0 \%$ agarose with an electrophoresis system (Sub-cell model 192; BioRad, USA).

\section{Statistical analyses}

Regeneration frequency was calculated from the ratio of explants with adventitious regeneration to bud total explants. Regeneration frequency of resistance bud was calculated from the ratio of the number of regeneration resistance adventitious buds to total explants. Transformation frequency was calculated from the ratio of successfully transformed transplanted Micro-Tom plants to total explants.

\section{RESULTS}

Several factors have been reported to affect transformation frequency. In this study, contamination rate, necrosis rate, mortality, cut-surface browning rate, and undamaged explant rate were tested.

\section{Contamination rate comparison}

We studied factors influencing contamination rate, and sorted in descending order, they 
were as follows: co-cultivation time $>$ concentration of carbenicillin $>$ bacterial suspension concentration $>$ time of dip in the bacterial suspension (Tables 2 and 3). In these experiments, we observed that the main factor affecting the contamination rate of transformation was cocultivation time. Increasing co-cultivation time from 1 to 2 days markedly increased the contamination rate. Table 3 shows the highly significant difference between 1 and 2 days, whereas the differences between co-cultivation times of 1 day and 3 or 4 days were not significant. The second factor influencing contamination rate of transformation was concentration, both of carbenicillin and of bacterial suspension $(\mathrm{P}<0.05)$. The time of dip in the bacterial suspension had no significant influence. The main factor influencing contamination rate of transformation was co-cultivation time. When carbenicillin reached a fairly high level, reducing the co-cultivation time decreased the contamination rate. A comparison of contamination rates showed that a bacterial suspension at a concentration of $0.5 \times 10^{8} \mathrm{cells} / \mathrm{mL}\left(\mathrm{OD}_{600}=0.5\right)$, co-cultivation of 1 day, and a bacterial concentration of $400 \mathrm{mg} / \mathrm{L}$ minimized contamination rate.

\begin{tabular}{|c|c|c|c|c|c|}
\hline Orthogonal combination & Contamination rate & Necrosis rate & Cut-surface browning rate & Mortality & Undamaged rate \\
\hline 1 & 34.8 & 71.5 & 33.1 & 21.5 & 0.0 \\
\hline 2 & 100.0 & 71.5 & 100.0 & 0.0 & 0.0 \\
\hline 3 & 73.8 & 83.8 & 93.8 & 0.5 & 0.0 \\
\hline 4 & 100.0 & 74.1 & 100.0 & 6.3 & 0.0 \\
\hline 5 & 94.5 & 88.9 & 100.0 & 0.0 & 5.6 \\
\hline 6 & 81.3 & 68.8 & 87.5 & 12.5 & 0.0 \\
\hline 7 & 100.0 & 91.7 & 100.0 & 0.0 & 0.0 \\
\hline 8 & 6.3 & 78.6 & 26.8 & 0.0 & 0.0 \\
\hline 9 & 100.0 & 92.9 & 100.0 & 0.0 & 0.0 \\
\hline 10 & 0.0 & 56.3 & 50.0 & 0.0 & 18.8 \\
\hline 11 & 100.0 & 69.1 & 100.0 & 0.0 & 0.0 \\
\hline 12 & 100.0 & 81.3 & 100.0 & 0.0 & 0.0 \\
\hline 13 & 100.0 & 73.0 & 100.0 & 0.0 & 0.0 \\
\hline 14 & 100.0 & 58.6 & 100.0 & 0.0 & 0.0 \\
\hline 15 & 6.3 & 50.0 & 18.8 & 18.8 & 31.3 \\
\hline 16 & 100.0 & 92.9 & 100.0 & 0.0 & 0.0 \\
\hline
\end{tabular}

\section{Necrosis rate comparison}

We studied factors influencing necrosis rate and observed that differences in the data range ( $\mathrm{R}$ values) for factor co-cultivation time and bacterial suspension concentration were both significant $(\mathrm{P}<0.05)$, but differences in carbenicillin concentration and the time of dip in the bacterial suspension were not significant for necrosis rate (see Tables 2 and 3). The necrosis rate increased with co-cultivation time and bacterial suspension concentration. The greater the necrosis, the fewer resistant calli we obtained. A comparison of necrosis rates showed that a bacterial suspension at a concentration of $0.5 \times 10^{8}$ cells $/ \mathrm{mL}\left(\mathrm{OD}_{600}=0.5\right)$ and co-cultivation time of 1 day minimized necrosis rate.

\section{Mortality comparison}

We studied factors that influence mortality and observed that differences in the $\mathrm{R}$ values for co-cultivation time and carbenicillin concentration were both significant $(\mathrm{P}<0.05)$, 


\begin{tabular}{|c|c|c|c|c|c|}
\hline & Level & $\begin{array}{l}\text { Concentration of bacterial } \\
\text { suspension }\left(\mathrm{OD}_{600}\right)\end{array}$ & $\begin{array}{l}\text { Time of dip in bacterial } \\
\text { suspension (min) }\end{array}$ & $\begin{array}{l}\text { Co-cultivation } \\
\text { time (days) }\end{array}$ & $\begin{array}{c}\text { Concentration of } \\
\text { carbenicillin }(\mathrm{mg} / \mathrm{L})\end{array}$ \\
\hline \multirow[t]{6}{*}{ Contamination rate } & $\mathrm{K} * 1$ & 82.313 & 79.013 & 11.825 & 83.700 \\
\hline & $\mathrm{K} 2$ & 70.313 & 75.175 & 100.000 & 76.563 \\
\hline & K3 & 70.000 & 70.000 & 88.750 & 67.050 \\
\hline & K4 & 76.563 & 75.000 & 98.613 & 71.875 \\
\hline & $\mathrm{R}^{*}$ & 12.313 & 9.013 & 88.175 & 16.650 \\
\hline & $\mathrm{P}$ & 0.192 & 0.558 & 0.0001 & 0.0878 \\
\hline \multirow{6}{*}{ Necrosis rate } & $\mathrm{K} 1$ & 81.550 & 75.525 & 64.063 & 75.725 \\
\hline & $\mathrm{K} 2$ & 63.750 & 72.900 & 87.200 & 73.013 \\
\hline & $\mathrm{K} 3$ & 73.613 & 78.425 & 76.688 & 80.438 \\
\hline & K4 & 81.688 & 73.750 & 72.650 & 71.425 \\
\hline & $\mathrm{R}$ & 17.938 & 5.525 & 23.138 & 9.013 \\
\hline & $\mathrm{P}$ & 0.302 & 0.953 & 0.209 & 0.833 \\
\hline \multirow{6}{*}{ Mortality } & $\mathrm{K} 1$ & 5.363 & 8.488 & 10.050 & 5.363 \\
\hline & $\mathrm{K} 2$ & 3.125 & 4.688 & 0.000 & 0.000 \\
\hline & $\mathrm{K} 3$ & 4.813 & 0.125 & 3.250 & 0.125 \\
\hline & K4 & 1.563 & 1.563 & 1.563 & 9.375 \\
\hline & $\mathrm{R}$ & 3.800 & 8.363 & 10.050 & 9.375 \\
\hline & $\mathrm{P}$ & 0.836 & 0.305 & 0.176 & 0.162 \\
\hline \multirow[t]{6}{*}{ Cut-surface browning rate } & $\mathrm{K} 1$ & 83.263 & 80.138 & 32.150 & 83.263 \\
\hline & $\mathrm{K} 2$ & 84.375 & 79.688 & 100.000 & 81.700 \\
\hline & $\mathrm{K} 3$ & 78.125 & 80.138 & 95.313 & 85.938 \\
\hline & $\mathrm{K} 4$ & 81.700 & 87.500 & 100.000 & 76.563 \\
\hline & $\mathrm{R}$ & 6.25 & 7.8125 & 67.85 & 9.375 \\
\hline & $\mathrm{P}$ & 0.203 & 0.049 & 0.0001 & 0.038 \\
\hline \multirow[t]{6}{*}{ Undamaged explant rate } & K1 & 1.388 & 0.000 & 12.500 & 0.000 \\
\hline & $\mathrm{K} 2$ & 4.688 & 9.200 & 0.000 & 0.000 \\
\hline & $\mathrm{K} 3$ & 7.813 & 0.000 & 0.000 & 6.075 \\
\hline & $\mathrm{K} 4$ & 0.000 & 4.688 & 1.388 & 7.813 \\
\hline & $\mathrm{R}$ & 7.813 & 9.200 & 12.500 & 7.813 \\
\hline & $\mathrm{P}$ & 0.0039 & 0.0005 & 0.0001 & 0.001 \\
\hline
\end{tabular}

$\overline{\mathrm{K}}=$ mean value of the test corresponding to a factor in the same level; $\mathrm{R}=\mathrm{K}_{\max }-\mathrm{K}_{\min }$. Asterisks $\left(\mathrm{K}^{*} 1\right)$ and $\left(\mathrm{R}^{*}\right)$ mean the note of $\mathrm{K}$ and $\mathrm{R}$.

but differences in the bacterial suspension concentration and the time of dip in the bacterial suspension were not significant (see Table 3). In these experiments, we observed that the main factor affecting mortality of transformation was co-cultivation time and carbenicillin concentration. Increasing co-cultivation time and carbenicillin concentration can lead to a significantly high rate of mortality. The results indicated that 2 and 4 days of co-cultivation and 300 and $400 \mathrm{mg} / \mathrm{L}$ carbenicillin concentration minimized mortality.

\section{Cut-surface browning rate comparison}

The $\mathrm{R}$ values in Tables 2 and 3 show that experimental factors influenced cut-surface browning rate in this order: co-cultivation time $>$ carbenicillin concentration $>$ time of dip in the bacterial suspension $>$ bacterial suspension concentration. The $\mathrm{R}$ value of necrosis rate is also about much larger than other factors. Differences in co-cultivation time, carbenicillin concentration, and the time of dip in the bacterial suspension were highly significant $(\mathrm{P}<$ 0.01). Differences in bacterial suspension concentration also showed significance $(\mathrm{P}<0.05)$. Consequently, all factors in this experiment showed significant effects on cut-surface browning rate, which was a key indicator of the ability of newborn resistant callus. The results indicated that a bacterial suspension at a concentration of $0.5 \times 10^{8}$ cells $\left./ \mathrm{mL}_{(} \mathrm{OD}_{600}=0.5\right), 1$ day 
of co-cultivation, an infection time of $5 \mathrm{~min}$ in the bacterial suspension, and a carbenicillin concentration of $500 \mathrm{mg} / \mathrm{L}$ minimized the cut-surface browning rate.

\section{Undamaged explant rate comparison}

The $\mathrm{R}$ values in Tables 2 and 3 show that experimental factors influenced the rate of undamaged explants in this order: co-cultivation time $>$ time of dip in the bacterial suspension $>$ bacterial suspension concentration $>$ carbenicillin concentration, and the differences in all factors were highly significant. The results showed that a bacterial suspension at a concentration of $0.5 \times 10^{8}$ cells $/ \mathrm{mL}\left(\mathrm{OD}_{600}=0.5\right), 1$ day of co-cultivation, an infection time of $5 \mathrm{~min}$ in the bacterial suspension, and a carbenicillin concentration of $500 \mathrm{mg} / \mathrm{L}$ maximized the rate of undamaged explants.

\section{Molecular identification and statistics of transgenic plants}

Phenotypically normal and fertile plants were grown to maturity in the greenhouse. We obtained 10 lines of 33 transgenic tomato plants from 19 lines of regeneration (Figures 1 and 2). The optimized protocol was used to obtain a regeneration frequency averaging $9.1 \%$ and a $5.1 \%$ regeneration frequency of resistance bud (Figures 3 and 4). Currently, average transformation frequencies are approximately $3.9 \%$.

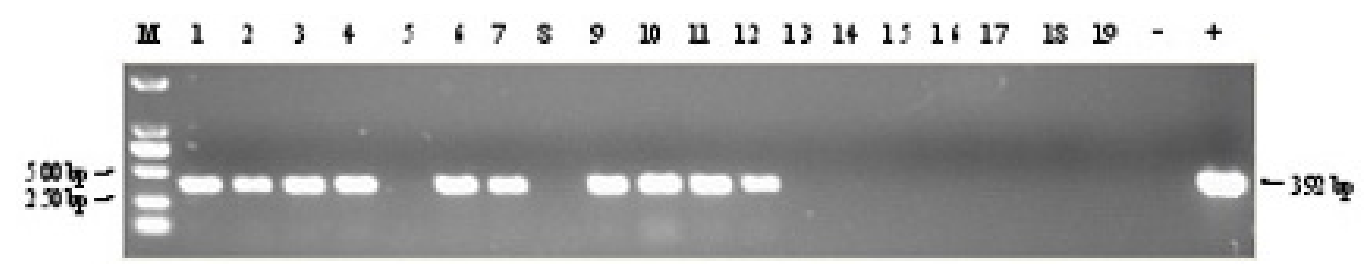

Figure 1. PCR identification of transgenic Micro-Tom plants with the HPTII gene. Lane $M=$ DNA marker DL2000; lanes 1-19 = independent hygromycin-resistant plants; lane $+=$ plasmid of pCAMBLA1300-2A11-INH as the positive control; lane - = non-transgenic Micro-Tom plant.

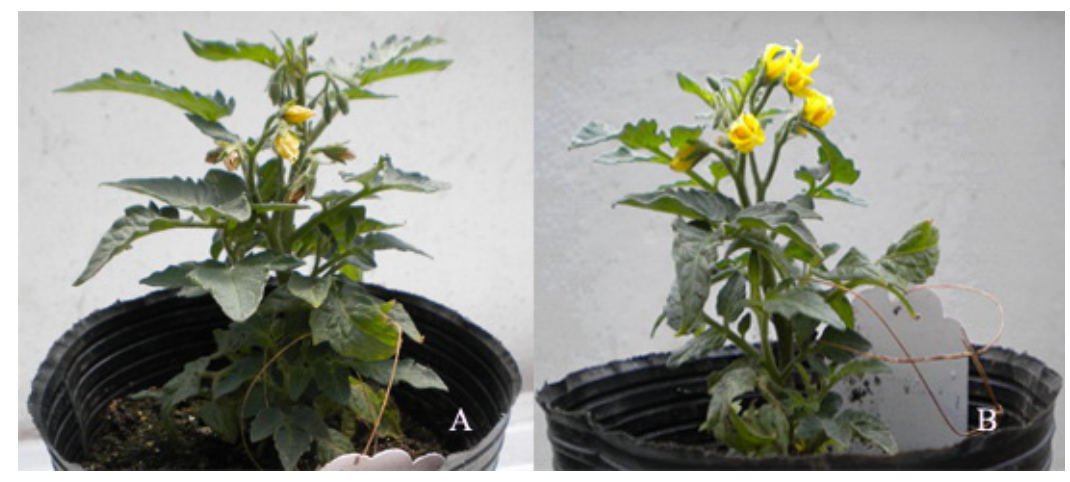

Figure 2. The growth of transgenic Micro-Tom plants. A. Control. B. Transgenic plant. 


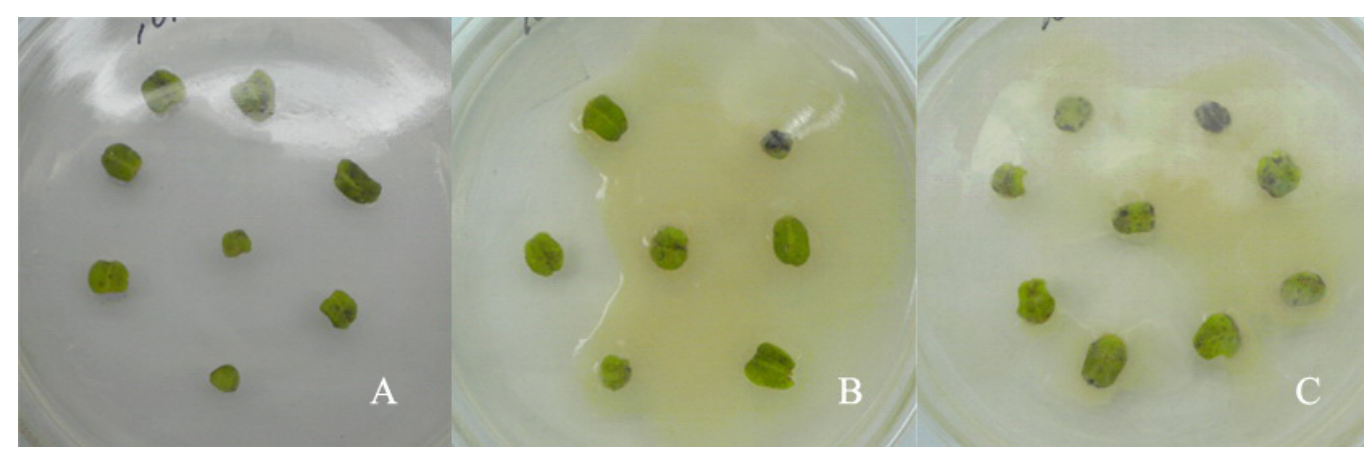

Figure 3. Influence of the bacterial suspension on Micro-Tom cotyledon for the orthogonal combination 15, 10 and 5. A. Orthogonal combination 15. B. Orthogonal combination 10. C. Orthogonal combination 5.

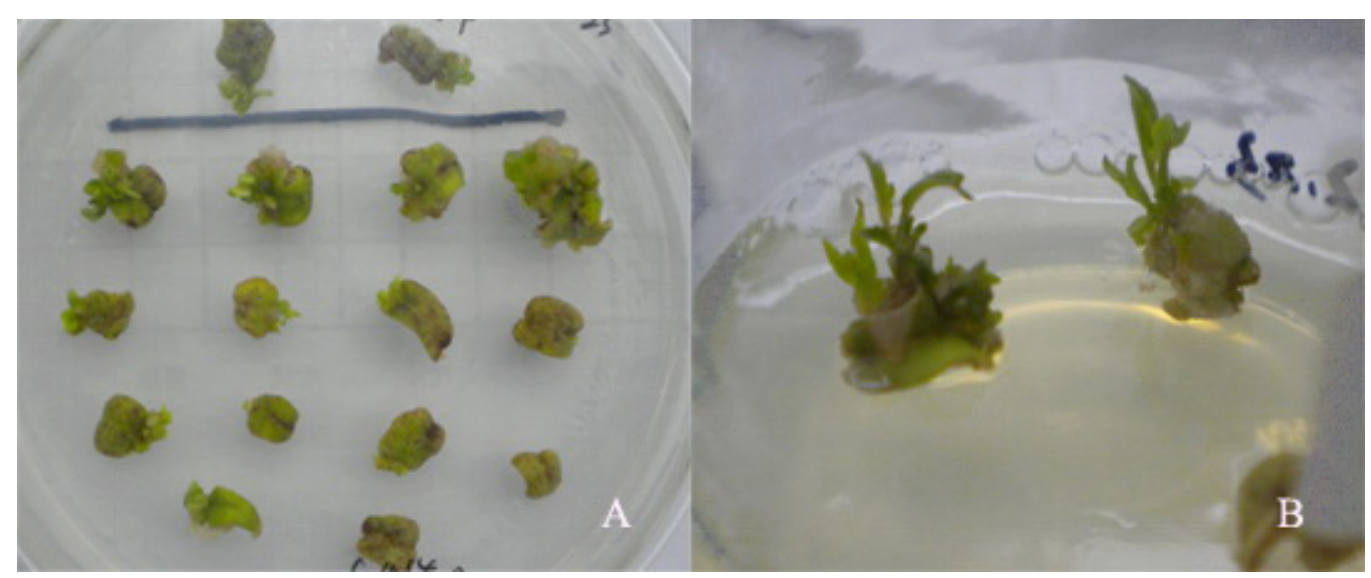

Figure 4. Regeneration of cotyledon growth after adsorbing the bacterial suspension. A. Infected regeneration callus. B. Infected regeneration shoots.

\section{DISCUSSION}

The results of our study indicated that co-cultivation time was the main factor influencing transformation: too long a time resulted in multiplied bacteria and too short a time decreased transformation frequency. In our study, 1 day was an appropriate time span for co-cultivation, which differs from times reported elsewhere (Biao et al., 1994; Liqiong et al., 2002; Carolina and Francisco, 2004; Yan et al., 2004; Frary and Van Eck, 2005; Kou et al., 2007), which may be related to the genotypes of tomato and the use of different plant tissue.

Carbenicillin concentration was the second factor that affected cut-surface browning rate, contamination rate, and mortality. In our trials, carbenicillin could not suppress the growth of A. tumefaciens when colonies were observed on the plate. Consequently, we needed to regulate the carbenicillin concentration to inhibit $A$. tumefaciens early in the selection culture. However, cut-surface browning rate showed strong effects on transformation frequencies. Infection caused explants to turn brown, induced necrosis, and reduced callus develop- 
ment. Our results indicated that $500 \mathrm{mg} / \mathrm{L}$ carbenicillin was the optimal concentration for suppressing $A$. tumefaciens in early selection culture with minimal poisonous effects.

Bacterial suspension concentration had the strongest effect on necrosis rate in every combination. We conclude that the occurrence of necrosis might be associated with factors outside of our experimental variables. In other word, bacterial suspension concentration was not a key factor in successful transformation. A bacterial suspension concentration of $0.5 \times 10^{8}$ cells $/ \mathrm{mL}\left(\mathrm{OD}_{600}=0.5\right)$ minimized necrosis rate.

The rate of undamaged explants was a comprehensive index of the association of infected explants and co-cultivation time, the time of dip in the bacterial suspension, bacterial suspension concentration, and carbenicillin concentration. This rate was the most important index of successful transformation, indicating whether explants remained green and exhibited vitality and whether they developed resistance calli. Orthogonal combination 15 was the best treatment with which to obtain a high rate of undamaged explants (see Table 4).

Table 4. Variance analysis of different levels for each factor.
\begin{tabular}{lccc}
\hline Orthogonal combination & Average & $5 \%$ significant difference & $1 \%$ significant difference \\
\hline 15 & 31.25 & a & A \\
10 & 18.75 & b & B \\
5 & 5.55 & c & C \\
\hline
\end{tabular}

In Agrobacterium-mediated transformations in tomato, transformation frequencies are not only related to co-cultivation time, the time of dip in the bacterial suspension, and bacterial suspension and carbenicillin concentrations but also correlated with the plasmid of transformation, which contains various selection marker genes such as kanamycin (Kan), that affect genetic transformation. In many traits of interest, because the enzymatic assay for Kan had minimal effects on plant regeneration compared with that for HPTII, most transformation experiments have used plasmids of Kan as selection markers (Li et al., 2007; Ying et al., 2008; Chen et al., 2010). The transformation efficiency is not a limiting factor; several authors have reported transformation rates with efficiencies ranging from 12 to 14\% (Koonneef et al., 1986; McCormick et al., 1986; Hamza and Chupeau, 1993; Van Roekel et al., 1993; Ellul et al., 2003; Carolina and Francisco, 2004). Two publications report transformation frequencies of only approximately 1\% (Chyi and Phillips, 1987; Pozueta-Romero et al., 2001), whereas others report efficiencies up to 40\% (Hyeon et al., 2007; Zen and Cheng, 2008). Nevertheless, the only publication of Agrobacterium-mediated transformation with a plasmid harboring HPTII as the reporter gene reported resistance shoot transformation frequencies of only $3 \%$ (Zen and Cheng, 2008). In our trail, resistance shoot transformation frequency was 5.1\%, with 33 transgenic plants obtained and transformation frequencies averaging 3.9\%. This frequency is lower than those reported with Kan as the selection marker but higher than that reported with HPTII as the selection marker, indicating that the orthogonal design method established a high-throughput transformation protocol for an HPTII selection plasmid. The use of this technique opens new prospects for the selection of plasmids for plant transformation.

Orthogonal design is more widely used in industry than in agriculture. Using orthogonal design, we established a high-throughput transformation protocol for the Micro-Tom tomato. The results suggest that the protocol presented here is useful for introducing functional genes into these plants. 


\section{ACKNOWLEDGMENTS}

Research supported by grants from the National Natural Science Foundation of China (grant \#30971999), the National Key Basic Research Special Funds of China (grant \#2009CB119000), and the Key Laboratory of Liaoning Province Education Department (grant \#2009S092).

\section{REFERENCES}

Biao ZY, Xia HL and Lin GZ (1994). Genetic transformation of antisense cDNA of polygalacturonase in tomato and transgenic plant regeneration. Acta Hort. Sin. 1: 305-306.

Carolina C and Francisco ACM (2004). Tomato transformation and transgenic plant production. Plant Cell Tiss. Organ Cult. 76: 269-275.

Chen SC, Liu AR, Wang FH and Zhou Z (2010). Establishment of Agrobacterium-mediated genetic transformation system of Micro-Tom. Acta Agricult. Boreali-Sin. 25: 112-115.

Chyi YS and Phillips GC (1987). High efficiency Agrobacterium-mediated transformation of Lycopersicon based on conditions favorable for regeneration. Plant Cell Rep. 6: 105-108.

Ellul P, Garcia-Sogo B, Pineda B, Rios G, et al. (2003). The ploidy level of transgenic plants in Agrobacterium-mediated transformation of tomato cotyledons (Lycopersicon esculentum Mill.) is genotype and procedure dependent [corrected]. Theor. Appl. Genet. 106: 231-238.

Frary A and Van Eck J (2005). Organogenesis from transformed tomato explants. Methods Mol. Biol. 286: 141-150.

Hamza S and Chupeau Y (1993). Re-evaluation of conditions for plant regeneration and Agrobacterium-mediated transformation from tomato (Lycopersicon esculentum). J. Exp. Bot. 44: 1873-1845.

Hui YG, Ying JY and Zhe JC (2007). Studies on genetic transformation system of tomato. J. Jilin Teachers Inst. Eng. Tech. 23: 56-58.

Hyeon JS, Sayaka U, Shin W and Hiroshi E (2007). A highly efficient transformation protocol for Micro-Tom, a model cultivar for tomato functional genomics. Plant Cell Physiol. 47: 426-431.

Koonneef M, Hanhart C, Jongsma M, Toma I, et al. (1986). Breeding of a tomato genotype readily accessible to genetic manipulation. Plant Sci. 45: 201-208.

Kou XH, Luo YB, Tian HQ and Shi Y (2007). Genetic transformation processing of tomatoes with anti-PG gene. Food Sci. 28: 187-191.

Li YC, Zhu BZ and Luo YB (2007). Agrobacterium-mediated transformation of tomato with anti-LeERF2 gene. Food Sci. 28: 327-331.

Ling W, Liang S, Ping L, Wang YJ, et al. (2009). Cloning of ABA biosynthesis key enzyme NCED gene from tomato fruit and its RNA interference genetic transformation. J. China Agri. Univ. 14: 54-60.

Liqiong Z, Shaosong Z, Hongmei C, Chengyun L, et al. (2002). Studies on transformation of antisense ACCase gene into tomatoes. J. Yunnan Univ. 24: 393-397.

McCormick S, Niedermeyer J, Fry J, Barnason A, et al. (1986). Leaf disc transformation of cultivated tomato ( $L$. esculentum) using Agrobacterium tumefaciens. Plant Cell Rep. 5: 81-84.

Meissner R, Jacobson Y, Melamed S, Levyatuv S, et al. (1997). A new model system for tomato genetics. Plant J. 12: $1465-1472$.

Min YS (2009). Mathematical Statistics. Science Press, Beijing.

Murashige T and Skoog F (1962). A revised medium for rapid growth and bioassays with tobacco tissue cultures. Plant Physiol. 15: 473-497.

Pozueta-Romero J, Houlné G, Cañas L, Schantz R, et al. (2001). Enhanced regeneration of tomato and pepper seedling explants for Agrobacterium-mediated transformation. Plant Cell Tiss. Organ Cult. 67: 173-180.

Ross PJ (1988). Taguchi techniques for quality engineering. Loss function, orthogonal experiments, parameter and tolerance design. McGraw-Hill, New York.

Van Roekel JSC, Damm B, Melchers LS and Hoekema A (1993). Factors influencing transformation frequency of tomato (Lycopersicon esculentum). Plant Cell Rep. 12: 644-647.

Xia ML, Wei SL and Fu JL (2004). Progress on genetic transformation of tomato mediated by Agrobacterium tumefaciens. J. Northeast Agricult. Univ. 35: 129-134.

Yan H, Xang GC and Jun CL (2004). Agrobacterium-mediated transformation of tomoto with IPT and ETR121 gene and plant regeneration. J. Nanjing Normal Uiniv. 27: 83-87. 
Ying CY, Huang XQ, Guo YQ, Zhong LL, et al. (2008). Optimization of tomato genetic transformation, kanamycinresistant screening and seed selection. Nan. Fang Yi Ke Da. Xue Xue Bao 28: 1117-1122.

Zen C and Cheng Z (2008). Optimal research on Agrobacterium-mediated transformation systems of tomato (Lycopersicon esculentum). J. Zhejiang Univ. (Agricult. Life Sci.). 34: 615-620. 